\title{
O professor artista na universidade brasileira : questões e desafios
}

\section{Daniel Lemos Cerqueira}

Resumo : Pretende-se abordar a situação de trabalho do professor artista nas Instituições Federais de Ensino Superior (IFES), com vistas à instauração da pratica do métier enquanto pesquisa. São tratadas questões sobre o plano de carreira e os possiveis entraves que este possa representar para a produção artística. Apontam-se algumas iniciativas recentes voltadas a atenuar esses problemas, sucedendo-se de uma discussão sobre a pesquisa artística e a prática como pesquisa. Conclusões apontam para a necessidade do diálogo entre professores artistas e a comunidade acadêmica, destacando a institucionalização da prática como pesquisa.

Abstract: In this paper the author aims to approach particular aspects of the working situation regarding professional artists who develop a teaching career within the Brazilian Federal University System (IEFS), mainly regarding the artistic research which from a career plan's perspective, may undamaged the artistic production itself. Recent initiatives are explored, in the search of possible solutions for this problem; discussion which follows evokes artistic research and the practice as research. Conclusions suggest the need of a dialogue among these professionals and the academic community, in order to consistently establish the practice of art as research.

\section{Contextualização}

Há alguns anos, li uma crítica de jornal do professor Dr. Charles Kiefer (PUC/RS) que me trouxe inquietações. Essa nota ilustra muito bem a realidade da produção artística meio acadêmico brasileiro. Guardei-a em meus arquivos, sob a perspectiva de que um dia teria mais maturidade para tratar "academicamente" acerca dessa questão. Compartilho um trecho dessa crítica a seguir:

Sou professor universitário e escritor. E como acadêmico-escritor vivo uma situação patética, para não dizer hilária. Escrevo um romance. Que me toma anos de pesquisa, anos de trabalho para 
redigi-lo. Não faço citações, não transcrevo textos alheios. Minha bibliografia é o conjunto de obras que fui capaz de ler ao longo de toda a minha vida, somada aos filmes que vi, às músicas que ouvi, às experiências que vivi. Como sou professor-universitário de pósgraduação em Escrita Criativa, vivo acossado pelo que se conhece por produção acadêmica, dados que precisam ser lançados no Currículo Lattes, por que se eu não tiver uma determinada pontuação, serei descredenciado; meu curso, no caso a Faculdade de Letras, será prejudicado no ranking nacional das universidades brasileiras. Meu romance, tão demorada e pacientemente elaborado, alguns me tomam quatro ou cinco anos de trabalho, atividade em que apliquei engenho e arte, em que procurei o que a crítica literária chama de tour-de-force, não vale praticamente nada como produção acadêmica. E depois que publiquei o romance, vivo uma situação verdadeiramente kafkiana. Um aluno faz um ensaio de algumas páginas sobre o meu romance, publica suas considerações numa revista de Qualis A e recebe uma pontuação maior que a minha em termos de produção acadêmica... (Kiefer, 2012)

A questão apontada por Kiefer é muito semelhante à relatada por vários colegas que atuam nas áreas de Música, Artes Visuais, Teatro e Dança - que, inclusive, é inserida pela Coordenação de Aperfeiçoamento de Pessoal de Nível Superior (CAPES) em uma "grande área" definida por "Linguística, Letras e Artes", classificação que dilui a relevância das Artes como área do conhecimento'. Outra situação que gera muito desconforto ocorre quando conversamos com colegas de outras áreas que não tem a produção artística entre suas obrigações acadêmicas. Sempre há perguntas sobre "quais são as suas leituras atuais", "em que periódicos você é parecerista", "com que autores você trabalha" ou até

\footnotetext{
1 A diversidade das matrizes curriculares entre apenas dois cursos de graduação nas Artes (Música, Teatro, Artes Visuais, Dança ou Cinema) é muito maior do que entre qualquer uma das graduações das Ciências Exatas (Engenharia, Matemática, Física ou Química, por exemplo) entre si, fato que necessita de uma urgente revisão da classificação imposta pela CAPES. Borgdorff (2012, p. 77-79) afirma que esse é um problema internacional: vários países adotam as definições das áreas de conhecimento provenientes do Manual Frascati.
} 
mesmo "quantos livros você publicou". Evidentemente, essas não são as questões mais importantes para quem se dedica também à produção artística. Ainda assim, isso gera uma sensação de que não estamos cumprindo plenamente com nossas obrigações docentes.

O caso dos Programas de Pós-Graduação é ainda mais grave, pois os professores artistas que desejam contribuir nesse campo se tornam "reféns" de políticas e metas de financiamento que não se adequam às reais necessidades da produção artística. O documento de avaliação da área de Artes/Música da CAPES afirma que para implementar um Mestrado, seu corpo docente "deve ter produção artística e bibliográfica continuada, regular, qualificada, e com comprovada relevância, vinculada às Áreas de Concentração e às Linhas de Pesquisa Propostas" (CAPES, 2013 , p. 6). Mais uma vez, a produção artística fica subordinada às condições impostas pelas metodologias e procedimentos da pesquisa "científica" qualitativa e quantitativa estabelecida na academia, definindo o perfil dos docentes que se esforçam para atuar nesse contexto adverso. Sobre os Mestrados Profissionais, que tem tido considerável sucesso certamente por suprirem uma demanda pela profissionalização que ainda é "estranha" ao meio acadêmico, eles também são norteados por essa mesma lógica (CAPES, 2013, p. 7-8).

Um dos pontos mais evidentes acerca dessa questão provém de como é pensado o plano de carreiras do Magistério Superior. É ele que dispõe sobre as competências e responsabilidades exigidas dos docentes universitários. No âmbito Federal, a legislação em vigor é a Lei n. ${ }^{\circ} 8.112$, de 11 de dezembro de 1990, alterada em diversos pontos por outras emendas e leis - em especial as Leis n. ${ }^{\circ} 12.272$, de 28 de dezembro de 2012 , e n. ${ }^{\circ} 12.863$, de 24 de setembro de 2013 . A partir dessa legislação, as universidades elaboram seus respectivos estatuto, regimento interno e resoluções específicas. Acerca das obrigações da docência em nível superior, a Lei $n .^{\circ}$ 12.272/2012 indica (Brasil, 2012): 
Art. $2^{\circ}$. São atividades das Carreiras e Cargos Isolados do Plano de Carreiras e Cargos de Magistério Federal aquelas relacionadas ao ensino, pesquisa e extensão e as inerentes ao exercício de direção, assessoramento, chefia, coordenação e assistência na própria instituição, além daquelas previstas em legislação específica.

Aqui, observamos o "tripé" em que estão alicerçadas as universidades brasileiras: ensino, pesquisa e extensão. A legislação é bem aberta, e oferece autonomia para as próprias instituições elaborarem sua resolução interna de planejamento acadêmico - que dispõe sobre as obrigações docentes com a respectiva carga horária. Outra resolução importante é a de progressão e promoção funcional, onde são listados os critérios e pontuação mínima para ascensão na carreira. Em boa parte das universidades federais, as resoluções procuram contemplar a produção artística - recitais, espetáculos cênicos e de dança, exposições de arte, escultura, criação de obras e trabalhos "técnicos" de iluminação, figurino, gravação, edição de som, entre vários exemplos - atribuindo mesmo que de maneira bem questionável "pontos" e "carga horária"2 para essas atividades.

Nesse contexto, surge o seguinte questionamento: um docente "tradicional", com produção bibliográfica e atuação no ensino, pesquisa e extensão, dispõe de 20 ou 40 horas semanais ${ }^{3}$ para realizar esses trabalhos. Já um docente artista dispõe do mesmo tempo para realizar todas essas mesmas obrigações, acrescentando-se ainda a produção artística. Como fica então a carga horária destinada à preparação e realização desse último tipo de atividade? O docente deverá fazê-la nas horas "vagas"? Certamente os atos de ler, escrever e publicar demandam

2 É importante reforçar que excetua-se a progressão horizontal para a classe de professor titular, cujos critérios focam muito mais nas obrigações do perfil acadêmico "tradicional". Um docente que possui produção artística dificilmente atingirá pontos suficientes para ascender a essa classe, prejudicando quem possui esse perfil.

3 O regime de Dedicação Exclusiva (D.E.) tem a mesma carga horária de 40 horas; a única diferença é o impedimento em exercer outra atividade profissional regular. 
um dispêndio de energia cognitiva semelhante a estudar um instrumento musical, ensaiar uma atividade coreográfica ou produzir uma obra de arte, por exemplo. Entretanto, os professores artistas não dispõem do dobro de tempo e de energia para fazê-los!

Todas essas questões, desde a progressão funcional ao perfil docente preterido em concursos públicos e em Programas de PósGraduação provém de como a legislação define a carreira docente. Seguindo o princípio da autonomia universitária, os professores artistas devem questionar: é essa perspectiva que queremos para nossa própria carreira?

Muitas queixas sobre as perspectivas da carreira para o professor artista são feitas informalmente e sem muita clareza sobre a raiz do problema, sendo essa a razão pela qual o presente trabalho pretende acrescentar ao debate a partir de uma investigação. Certamente as forças políticas que incidem sobre os professores artistas são esmagadoras, desencorajando a busca por mudanças. Muitos acabam se recolhendo a "seguir a cartilha" até sua aposentaria - fato compreensível diante dos desafios enfrentados por quem se dedica à produção artística em condições precárias. Porém, a revisão de literatura destacou que o tema tem sido debatido há pelo menos duas décadas, especialmente por acadêmicos das Artes Visuais. Contudo, é importante destacar que esse não é um problema exclusivo do Brasil: já existe uma discussão internacional sobre a "pesquisa artística". Vários países tem obtido sensíveis progressos no sentido de tornar o ambiente acadêmico propício ao desenvolvimento das Artes conforme suas próprias necessidades, entre eles Suécia, Finlândia, Reino Unido, Austrália e África do Sul. Essa discussão também será abordada aqui. 


\section{Uma análise comparativa do plano de carreiras}

Uma experiência que ajuda a pensar o plano de carreiras do Magistério Superior Federal é observar como outras instituições lidam com o "problema" do professor artista. Almeida (1992) e Arruda (2012) estudaram as Universidades Estaduais Paulistas, que contam com dois planos de carreira: o Magistério Superior tradicional (MS) e o Magistério Artístico (MA). O primeiro, assim como no plano do Magistério Superior Federal, é adaptado às necessidades de docentes cientistas e pesquisadores, tendo como principal característica a titulação, pois a pós-graduação stricto sensu no Brasil visa somente a formar pesquisadores. Já o segundo plano, criado em 1993, privilegia o notório saber e as experiências profissionais - assim como no plano de carreiras do Magistério do Ensino Básico, Técnico e Tecnológico Federal4. Segundo Arruda (2010, p. 54-55), o MA foi criado devido à falta de cursos de pós-graduação em Artes e de professores artistas com diploma de doutor, titulação mínima exigida para acesso à carreira de MS.

Dois são os benefícios evidentes da carreira de MA: 1) oferecer autonomia para os docentes artistas, que podem elaborar resoluções em acordo com a natureza de seu trabalho; e 2) ter melhores perspectivas para suas carreiras artísticas. Arruda acrescenta:

Quanto aos critérios de avaliação por mérito, o Magistério Artístico tem como base a produção e a divulgação da arte, tendo suas regras estabelecidas pela própria Unicamp. Para o professor do Magistério Superior do Instituto de Artes, assim como para os docentes desta carreira em outras áreas da Universidade, esse tipo de produção só pode ser considerado, caso esteja associado diretamente à sua linha de pesquisa: publicações em periódicos indexados internacionalmente, orientações e participação em

${ }_{4}^{4}$ Esse plano de carreiras é disposto nas mesmas leis que regem do Magistério Superior Federal. 
projetos de pesquisa são os produtos esperados, não só pelas instâncias da própria Unicamp, como pelos órgãos superiores de avaliação, como a Coordenação de Aperfeiçoamento de Pessoal de Nível Superior [...] (Arruda, 2012, p. 97)

Contudo, Arruda alerta (2012, p. 91-92) que com o tempo, a carreira de MA foi perdendo relevância institucional, em especial por pressão dos docentes da carreira de MS, que viam na anterior uma situação de "privilégio" por não serem obrigados a seguir muitas das regras institucionais. Essa desvalorização passou a se refletir financeiramente: em 2015, o salário do último nível da carreira de MA Professor Pleno III, em regime de RDIDP (Dedicação Exclusiva) - era de R\$ 10.765,33, enquanto o último nível de MS - Professor Titular MS6, em RDIDP - era de R\$15.400,48 (UNICAMP, 2015), uma diferença de 43,1\%. Outra questão importante é a restrição dos docentes da carreira de MA para ocupar cargos administrativos e participar de conselhos deliberativos, como os colegiados e conselhos superiores (Arruda, 2012, p. 97-98). No Instituto de Artes da UNICAMP, por exemplo, há professores na carreira de MS e de MA. Logicamente, as Artes constituem um valioso campo tanto para produção bibliográfica quanto à artística, entretanto, o benefício é que os docentes poderiam optar pela carreira que pretendem seguir. A desvantagem, segundo Arruda, é que:

[...] para os professores do Magistério Superior, submetidos às exigências máximas das regras acadêmicas, o Magistério Artístico especialmente o professor sem titulação nessa carreira - não preenche os requisitos mínimos necessários para habilitá-lo à academia. Não são, portanto, considerados iguais, quando se trata da investidura em cargos como os relatados. (Arruda, 2012, p. 99)

Focando especificamente na área de Música, podemos estabelecer uma relação com Aquino (2003, p. 103) ao tratar sobre a 
subárea de Performance Musical ${ }^{5}$, sendo essa a que mais se volta diretamente à produção artística - juntamente com a Composição, que em geral se insere na Musicologia. Aquino afirma que a Performance Musical, particularmente, já foi vista com descrédito perante as demais subáreas da Música, principalmente porque seu tipo principal de produção apresenta resistência para se adequar aos procedimentos científico-cartesianos da pesquisa tal como ela é institucionalizada na universidade brasileira - problema que, segundo o autor, já estaria ultrapassado, afirmação na qual concordamos em parte.

Assim, diante da experiência observada nas Universidades Estaduais Paulistas, é mais sensato buscar meios de reivindicar condições adequadas para as Artes dentro do plano de carreiras que já existe, evitando problemas futuros relacionados à polarização política, ao poder e à remuneração tais como os observados nas instituições estudadas.

\section{Algumas medidas recentes}

Em 2014, o Ministério da Cultura (MinC) e o Ministério da Educação (MEC) fecharam uma parceria para a realização do I Encontro Nacional do Ensino Superior das Artes, na Universidade Federal de Ouro Preto (UFOP). Na oportunidade, foram convidados coordenadores dos cursos de graduação em Artes Visuais, Artes Cênicas (Teatro), Cinema (Audiovisual e Comunicação), Dança, Design e Música de todas as Instituições Federais de Ensino (IFE). No evento, foram realizados grupos de trabalho para cada área, onde foram sugeridas propostas para as práticas de ensino, pesquisa, extensão, "cultura"6 e capacitação

\footnotetext{
5 Outros termos que se referem a essa subárea são "Práticas Interpretativas" e "Execução Musical".

6 Esse é um termo bastante complicado para as Artes: há contextos onde a palavra "cultura" desvaloriza a Arte como área do conhecimento e dissolve a
} 
relacionadas à produção artística. Foi a primeira vez na história do Brasil em que profissionais formados nas Artes foram consultados para a formulação de políticas educacionais e culturais voltadas a seu próprio setor.

Essa valiosa oportunidade de intercâmbio permitiu que questões de sensível relevância para as Artes fossem discutidas. Entre as mesmas, destacamos a sinalização dos problemas recorrentes enfrentados pelos professores artistas nas universidades brasileiras. $O$ documento resultante desse evento, a "Carta de Ouro Preto" - que não foi plenamente finalizado - pontua (Coordenadores dos Cursos de Artes das IFE, 2014, p. 1):

Esse momento, histórico para todos nós, ficará marcado pelo reconhecimento da urgente necessidade de implementação de condições adequadas para o pleno exercício da nossa sensibilidade, do nosso potencial criativo traduzido também, em nossa prática docente que, por sua vez, precisa alçar voo e romper com as estruturas de valores que imobilizam, emudecem, apagam e minam nossas ações.

O problema da pós-graduação nas Artes também foi apontado, havendo uma solicitação de condições mais adequadas para a atuação do professor artista nesse contexto. Foi mencionada, ainda, a necessidade de repensar o plano de carreiras do Magistério Superior (Coordenadores dos Cursos de Artes das IFE, 2014, p. 1):

Liberdade possível se consolida na valorização do artista-professor ou do professor-artista, portanto, nossa voz conclama uma ação quanto ao veto relativo ao acúmulo de atividades profissionais de docência e produção artística na Carreira de Magistério do Ensino Superior Federal (Lei n. ${ }^{\circ} 12.863 / 13$ ) que contrapõe-se às indicações

relevância da produção artística - fazendo com que seja vista como um "hobby" ou uma questão de menor relevância perante as relações sociais, econômicas e políticas próprias dos estudos sobre a "cultura". 
dos objetivos da Portaria n. $^{\circ} 18 / 2013$ bem como, em outra instância, aos critérios para a seleção de professores para o mestrado profissional. Nesses dois programas, espera-se que o professor possa atuar como artista para que, assim, seja capaz de retroalimentar sua prática docente.

No mesmo evento, foi apresentado o Programa "Mais Cultura nas Universidades", que consistiu no apoio à execução de projetos culturais com um a dois anos de duração nas IFES. Cerreti e Bezerra (2015, p. 134) destacam que o mesmo teve como objetivo central:

Desenvolver uma política nacional de articulação entre educação e cultura, que promova o reconhecimento das artes como campo do conhecimento e dos saberes culturais como elemento estratégico para qualificação do processo cultural e educativo, constituiu-se como o desafio central deste acordo interministerial.

Durante a apresentação desse programa, vários professores artistas destacaram ser necessário garantir a participação dos mesmos na formulação institucional das propostas, pois as administrações universitárias poderiam trabalhar com o conceito abrangente de "cultura" - perigosamente interpretado como "qualquer coisa". Aqui, surge uma questão importante e delicada para as Artes: a falta de políticas voltadas à valorização de profissionais capacitados. Segundo Botelho (2001, p. 74), é preciso atentar para o conceito de "cultura" na formulação de políticas públicas. Caso essa questão aparentemente simples não seja atendida, projetos que visam à democratização da formação artística, conscientização popular sobre as Artes como patrimônio e diversidade cultural, acesso de comunidades periféricas à produção artística, intercâmbio e criação de grupos de estudo próprios da área, entre algumas das ações propostas por professores artistas, acabam tendo seu 
espaço restringido diante da concorrência com iniciativas de áreas não relacionadas com as Artes, mas que se denominam "cultura"7.

Outra experiência que tem apresentado resultados positivos é a institucionalização de projetos culturais, a exemplo do que já ocorre com projetos de pesquisa e extensão. Gohr et al (2013) tratam sobre essa ação em uma IFE, focando nos procedimentos que a instituição deve adotar para que a realização de projetos culturais seja viabilizada nesse contexto. Toda universidade pública brasileira recebe uma verba para uso em ações culturais, e na maioria das instituições, esses recursos são geridos pela Pró-Reitoria de Extensão ou por algum Departamento ou Núcleo de Cultura ou Assuntos Culturais. Algumas instituições, a exemplo da Universidade Federal do Cariri (UFCA), criaram uma PróReitoria de Cultura, oferecendo maior autonomia para a gestão de projetos culturais. O exemplo dessa instituição tem trazido importantes reflexos para as práticas artísticas e culturais de sua localidade, especialmente devido à atenção especial que esse setor tem recebido da administração institucional. A figura abaixo apresenta o organograma da Pró-Reitoria de Cultura (Fig. 1), revelando os tipos de ações que estão sob sua atenção:

\footnotetext{
7 Cabe lembrar que as Artes, assim como as Humanidades, foram totalmente excluídas do Programa "Ciência Sem Fronteiras". Em contrapartida, quando se trata da "cultura" como "qualquer coisa", as Artes são obrigadas a dividir recursos com projetos que raramente possuem preocupações sobre as implicações históricas, econômicas, sociais e profissionais do trabalho artístico, ou seja: não tem a mesma visão abrangente e instruída do verdadeiro profissional da área.
} 
Figura 1 - Organograma da PROCULT/UFCA.

Fonte: https://www.ufca.edu.br.

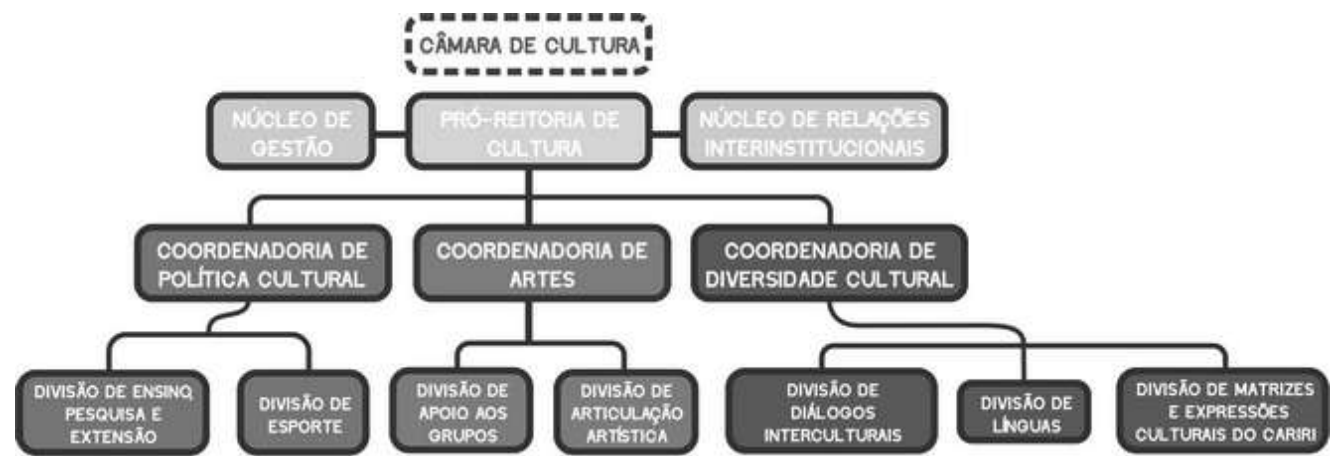

É interessante observar nesse organograma que há uma coordenadoria para as Artes separada daquela dedicada à "Cultura", provavelmente para evitar a desvalorização da produção artística e, consequentemente, da Arte como área do conhecimento - questão que abordamos há pouco. Porém, destacamos ser fundamental que os setores institucionais ligados à cultura dialoguem - e, preferencialmente, envolvam - os professores artistas. Infelizmente, há vários casos onde as unidades acadêmicas de formação artística são vistas apenas como um "escolão" pela administração institucional, não havendo interesse de PróReitorias ou de Departamentos de Cultura em dialogar com professores, técnicos e alunos das Artes. Contudo, esse diálogo pode acontecer quando não há recursos, a partir de convites para realizar atividades artísticas gratuitas - um problema grave e muito recorrente também mencionado no encontro de Ouro Preto. Uma breve analogia ajuda a entender essa questão: professores e alunos de Medicina atendem pacientes de graça para a comunidade acadêmica? Professores e alunos de Engenharia prestam consultoria voluntária para empresas? Então porque essa concepção de que professores e alunos de Música, Teatro, Artes Visuais e Dança tem de se apresentar gratuitamente, em "nome da instituição" ou sob o fraco argumento da "chance de visibilidade"? É 
imperativo que a universidade colabore para a afirmação das Artes como uma profissão, ao invés de repetir os mesmos problemas que o artista vivencia na sociedade.

\section{A questão da pesquisa artística}

O musicólogo holandês Henk Borgdorff tem sido uma das mais importantes personalidades do cenário internacional em defesa da institucionalização acadêmica da "pesquisa artística". Ele destaca que:

O debate sobre a prática como pesquisa nas artes, e em programas nos quais esse tipo de investigação pode ser realizado, recebeu destaque significante a partir das reformas universitárias ocorridas durante a década de 1990 no Reino Unido e na Escandinávia. (BORGDORFF, 2012, p. 34)

Já a coreógrafa sueca Efva Lilja (2015, p. 34-49) acrescenta que vários países da Europa tem apresentado relativo sucesso na inclusão dessa prática nas instituições de ensino superior, enquanto o teatrólogo Robin Nelson (2013, p. 8) acrescenta Austrália e África do Sul. Nelson alerta que por ser um tipo de prática investigativa recente, a pesquisa artística ainda não dispõe de um conjunto plenamente consolidado de metodologias para pesquisa e de literatura específica. Entretanto, o primeiro passo para resolver essa questão é permitir a institucionalização dessa prática, sendo necessário apenas tempo a esse amadurecimento (NELSON, 2013, p. 9-11). Já no Brasil, observamos apenas raras discussões pontuais sobre a pesquisa artística nas áreas de Dança e Teatro, revelando que o debate ainda é incipiente. Destacamos o artigo "Pesquisa Artística na Universidade: implicações epistemológicas, políticas e institucionais" (SETENTA, 2012) e a tradução do "Manifesto 
pela pesquisa performativa" (HASEMAN, 2015). Nesse último, o autor coloca que:

Estamos diante de um momento crucial no desenvolvimento da pesquisa. As metodologias estabelecidas das pesquisas qualitativa e quantitativa enquadram o que é legítimo e aceitável. No entanto, essas abordagens aprovadas não conseguem satisfazer as necessidades de um número crescente de pesquisadores guiadospela-prática, especialmente nas artes, mídia e design. Dentro do binário da pesquisa quantitativa e qualitativa, esses pesquisadores guiados-pela-prática têm se esforçado para formular metodologias sensíveis a suas crenças fundamentais sobre a natureza e o valor da investigação. (HASEMAN, 2015, p. 41)

Aqui, vamos tratar sobre o que é pesquisa artística. Borgdorff (2012, p. 37-39) apresenta três tipos de metodologia afins à mesma. São eles:

1) Pesquisa sobre artes ("research on the arts"): são as investigações onde a prática artística é o objeto de estudo, no sentido mais amplo desse termo. Buscam conclusões válidas sobre a prática artística em uma perspectiva teórica, implicando em uma distância hipotética - e idealizada - entre pesquisador e objeto. Usam-se estratégias de pesquisa já consolidadas no meio acadêmico. Exemplos de disciplinas da "pesquisa sobre artes" são musicologia, história da arte, estudos sobre teatro, mídia e literatura. Pesquisas das ciências sociais que tem a prática artística como objeto de pesquisa também pertencem a essa categoria. A qualidade que agrega todas essas diferentes disciplinas é a abordagem focada na "reflexão" e "interpretação", sendo históricas e hermenêuticas, filosóficas e estéticas, críticas e analíticas, reconstrutivas ou desconstrutivas, descritivas ou explanatórias.

2) Pesquisa para as artes ("research for the arts"): são as investigações caracterizadas como pesquisa aplicada, em um sentido restrito. Aqui, a prática artística constitui o objetivo da investigação, e 
não o objeto. Oferecem novas concepções e ferramentas que podem ser utilizadas na prática artística de alguma forma, e podem fazer uso dos métodos de investigação já estabelecidos. Exemplos de trabalhos nessa categoria são aqueles que tratam sobre técnicas de afinação do piano, utilização de equipamentos eletrônicos na interpretação ao vivo (em Música, Dança ou Teatro) ou análise de materiais e seu uso em esculturas. Logo, visam a contemplar ferramentas e conhecimentos que podem gerar interferência direta nos processos criativos e na produção artística.

3) Pesquisa nas artes ("research in the arts"): são as investigações onde a prática artística assume a posição tanto de objeto quanto de processo metodológico. Portanto, não admitem separação entre pesquisador - o artista - e objeto - a prática artística. Também não cabe a distinção entre teoria e prática, pois é a partir dessa última que os problemas da investigação são detectados, analisados e resolvidos. Segundo Borgdorff (2012, p. 39), "conceitos e teorias, experiências e compreensões estão inter-relacionados com a prática artística; e, parcialmente por essa razão, a arte é sempre reflexiva". Alguns exemplos de pesquisa nessa linha são trabalhos onde se pretende investigar um repertório musical que não mais circula, apresenta-lo e gravá-lo, frente à falta de registros sonoros do mesmo; estudar algum problema fisiológico resultante da prática instrumental, analisa-lo e buscar resolvê-lo na própria prática; preparar um repertório e depois apresenta-lo em projetos culturais, analisando criticamente as políticas de cultura em vigência, os espaços de circulação e a aceitação ou não do repertório escolhido; ou apresentar uma criação artística e verificar seu impacto no público, através da análise de sua recepção.

Destacamos ser fundamental observar que a concepção apresentada de pesquisa artística não exclui nenhum outro tipo de trabalho acadêmico já realizado nas Artes e na Música. Pelo contrário: agrega todos eles, buscando acrescentar a "pesquisa nas artes". Esse 
último - o mais problemático certamente por não dispor de metodologias de investigação estabelecidas tradicionalmente na academia, além de colocar em xeque o que se entende por "conhecimento", "ciência" e "pesquisa" nesse meio - traz um conceito importante: a prática como pesquisa ("practice as research") ${ }^{8}$. Aqui, a formação do artista é caracterizada pela internalização progressiva de conhecimentos e habilidades que envolvem todo o mecanismo sensóriomotor. Um músico ao interpretar uma melodia em seu instrumento, por exemplo, utiliza todo seu conhecimento sobre a peça, sobre linguagem e estruturação musical, seu senso estético, sua percepção musical e suas habilidades motoras desenvolvidas ao longo da vida, seja através de seus professores, de masterclasses ou de maneira autônoma, fazendo com que um simples gesto contenha toda a sua experiência musical. Logo, a prática como pesquisa envolve o que tem sido chamado de conhecimento incorporado ("embodied knowledge") ou "reflexão em ação" ("reflection in action"):

Acima de tudo, não há práticas da arte que não estejam saturadas de experiências, históricas e crenças; e não há acesso teórico a, ou interpretação de prática artística que não delineia parcialmente a própria prática no que ela é. Conceitos e teorias, experiências e entendimentos estão inter-relacionados com nas práticas da arte; e parcialmente, por essa razão, a arte é sempre reflexiva. A pesquisa nas artes busca então articular algum desse conhecimento incorporado através do processo criativo e do objeto de arte. (BORGDORFF, 2012, p. 38-39)

8 Nelson (2013, p. 10) discute a terminologia que vem sendo adotada por professores artistas, que também traz os termos "prática guiada pela pesquisa" ("practice-led research") e "pesquisa baseada na prática" ("practice-based research"). O autor defende que "prática como pesquisa" é o termo mais adequado, pois é o único que não corre o risco de denotar uma suposta hierarquia entre prática e pesquisa. É fundamental entende-las como elementos de igual importância. 
Outra característica da pesquisa nas artes, conforme reforça Lilja, é que o produto final dessas pesquisas assumem formas de apresentação variadas, sendo fundamental a figura do colega avaliador ("peer") - assim como nos procedimentos acadêmicos tradicionais:

Metodologias artísticas são aplicadas e o resultado final é apresentado da maneira mais adequada para o conteúdo e o tema do projeto, que pode ser uma performance, um concerto ou uma exibição, um texto ou uma mistura de diferentes mídias. A pesquisa pode ocorrer em grupos transdisciplinares e/ou com competências científicas ou por meio de um procedimento individual. O processo e os resultados são documentados e disponibilizados para avaliadores ["peers"]. (LILJA, 2015, p. 14)

Há, ainda, uma discussão sobre como diferenciar uma prática artística "usual" daquela que possui um viés investigativo. Lilja oferece a seguinte observação:

O artista que aborda tradições e práticas estabelecidas, trabalha sob a perspectiva de um pesquisador. $O$ artista que trabalha dentro de tradições e práticas estabelecidas pode ser um artista proeminente sem adotar uma perspectiva investigativa. É o posicionamento individual do artista em relação ao objetivo do seu trabalho que decide como definimos pesquisa. Quando trabalhamos na academia, aceitamos requerimentos como documentação de processos, descrição de metodologias e participamos de fóruns onde a pesquisa é discutida, analisada e compartilhada. Isso não significa que temos de utilizar técnicas de documentação dos campos da ciência, suas metodologias ou seus fóruns. Podemos fazer isso, mas podemos também desenvolver nossos próprios procedimentos sob uma concepção artística, dependendo das necessidades e condições da prática artística em mente. (LILJA, 2015, p. 15)

Apesar da perspectiva positiva na qual Lilja aborda a prática como pesquisa, Borgdorff adota uma visão mais crítica sobre a forte resistência que essa nova metodologia tem recebido do meio acadêmico - uma etapa que ainda será muito "dolorosa" no Brasil. Ele afirma que "nem todos os governos ainda estão maduros para esse tipo de reforma, e em 
alguns casos, eles ainda se atém persistentemente a uma divisão rígida entre educação acadêmica com pesquisa e treinamento profissional sem pesquisa" (BORGDORFF, 2012, p. 35). O musicólogo caracteriza três perfis de profissionais que recorrentemente se opõem à prática como pesquisa e, respectivamente, seus argumentos recorrentes:

Para alguns artistas praticantes, a requisição de fazer um pouco mais para articular sua investigação é vista como uma imposição não garantida além de sua cultura. Para alguns acadêmicos estabelecidos da arte, a prática como pesquisa não é aceitável como uma metodologia respeitável, e pode ser vista como uma nódoa em subdisciplinas de artes e mídia recém-estabelecidas. Para acadêmicos de disciplinas não-artísticas que dispõem de metodologias estabelecidas e métodos quantitativos e qualitativos, a prática como pesquisa é tanto um desafio para alguns em pressupostos fundamentais sobre o que é 'pesquisa' e 'conhecimento' quanto saber que haverá mais um competidor pelos escassos financiamentos para a pesquisa. (BORGDORFF, 2012, p. 4)

Trata-se, portanto, de um longo e árduo percurso até que a prática como pesquisa se estabeleça na universidade brasileira. Entretanto, na atual conjuntura, o primeiro passo é levantar a discussão em fóruns, associações e congressos acadêmicos das diversas áreas das Artes - e, em nosso caso particular, da Música. Felizmente, é possível nos respaldarmos em experiências promissoras que outros países já tem concretizado. Lilja finaliza:

É importante lembrar da complexidade em que nosso discurso da arte contemporânea Ocidental é baseado, e como estão intimamente interligadas educação, pesquisa e políticas culturais. Isso é um fato particularmente verdadeiro na atualidade, quando o desenvolvimento artístico acontece apesar de estratégias políticas ineficientes em vários países. Há um grande debate a ser feito sobre essa questão, pois somos às vezes imputados sob uma perspectiva 
utilitária, na qual nossas atividades são legitimadas meramente como inspiração criativa, reforço à inovação, aumento da produtividade, economia criativa, etc. Através da pesquisa em arte nós podemos influenciar e fortalecer o papel da arte em nossas sociedades multiculturais e diversas. (LILJA, 2015, p. 11)

\section{Epílogo}

Após conquistar um espaço de maior "respeito" no meio acadêmico (AQUINO, 2003), a subárea de Performance Musical, já adequada aos moldes da pesquisa acadêmica institucional, precisa agora caminhar em consonância com o discurso internacional da "prática como pesquisa" - um dos três ramos da metodologia de investigação afins à pesquisa artística. Com algumas iniciativas convergindo em busca de uma maior atenção para a produção artística e cultural nas instituições de ensino superior, é possível que haja abertura para o diálogo com outras áreas do conhecimento. Entretanto, o diálogo interno das Artes precisa prevalecer, pois os problemas gerados pelas más condições de trabalho provém justamente das barreiras institucionais. $O$ encontro de Ouro Preto, infelizmente, não gerou continuidade no debate entre os professores artistas. Tal fato provavelmente se deve ao acúmulo de atividades e funções que já incidem sobre os mesmos. Contudo, é preciso se esforçar para que as Artes busquem um espaço próprio para todos os tipos de produção que lhe são pertinentes, fato que só pode ser conquistado mediante a adequação das condições laborais dos profissionais da área. Na subárea de Performance Musical, sabemos da dificuldade que é manter a produção artística. Porém, estamos perdendo um precioso tempo por não discutir diversas questões urgentes. E entre essas, a institucionalização da prática como pesquisa seria uma conquista fundamental. Além de oferecer um ambiente propício para o desenvolvimento das Artes conforme suas reais particularidades, a sociedade seria, sem dúvida, a maior beneficiada. 


\section{Referências}

ALMEIDA, C. M. C. O trabalho do artista plástico na instituição de ensino superior: razões e paixões do artista-professor. Tese de Doutorado em Educação. 270f. Campinas: FAE/UNICAMP, 1992.

AQUINO, F. A. Práticas Interpretativas e a Pesquisa em Música: dilemas e propostas. In: XIV Congresso da Associação Nacional de Pesquisa e PósGraduação em Música (ANPPOM). Porto Alegre: UFRGS, 2003, p. 103-112.

ARRUDA, C. L. R. Arte, trabalho e profissão docente: contradições nas relações de trabalho dos artistas na universidade pública. Tese de Doutorado em Ciências Sociais. $211 \mathrm{f}$. Campinas: IFCH/UNICAMP, 2012.

Produção artística na universidade: relações de trabalho do professor-artista na Unicamp. Comunicações, ano 17, n. 2. Piracicaba: UNIMEP, jul-dez/2010, p. 51-64.

BORGDORFF, H. The Conflict of the Faculties: Perspectives on Artistic Research and Academia. Leiden: Leiden University Press, 2012.

BOTELHO, I. Dimensões da Cultura e Políticas Públicas. São Paulo em Perspectiva, v. 15(2). São Paulo: Fundação SEADE, 2001, p. 73-83.

BRASIL. Lei $n^{\circ}$ 12.272, de 28 de dezembro de 2012. Brasília, 2012.

CAPES. Documento de Área 2013: Artes/Música. Brasília: CAPES/DA, 2013. Disponível em http://www.capes.gov.br, último acesso em 05/04/2016.

CERRETI, C. C.; BEZERRA, T. G. O programa Mais Cultura nas Universidades como exemplo intersetorial de política pública entre Cultura e Educação. Interfaces Científicas - Humanas e Sociais, v. 4, edição especial. Aracaju: Grupo Tiradentes, nov-2015, p. 131-142.

COORDENADORES DOS CURSOS DE ARTES DAS IFE. Carta de Ouro Preto. Ouro Preto, 2014. Disponível em http://www.cultura.gov.br, último acesso em 05/04/2016.

GOHR, C. F.; SANTOS, L. C.; SCHWINGEL, A. W.; TALAMINI, E. Gestão de projetos de eventos culturais em uma universidade federal: análise de práticas e proposição de melhorias. Revista Administração, v. 6, n. 3. Santa Maria: UFSM, set-2013, p. 511-526.

HASEMAN, B. Manifesto pela pesquisa performativa. In: CERASOLI JÚNIOR, U. (org.). Resumos do Seminário de Pesquisas em Andamento PPGAC/USP, vol 3.1. São Paulo: USP, 2015, p. 41-53. 
KIEFER, C. A arte não pode ser inferior à ciência. Zero Hora, Porto Alegre, p. 6, 26 mai. 2012.

LILJA, E. Art, Research, Empowerment: On the Artist as Researcher. Estocolmo: Elanders Sweden AB, 2015.

NELSON, R. Practice as Research in the Arts: Principles, Protocols, Pedagogies, Resistances. Basingstoke: Palgrave Macmillan, 2013.

SETENTA, J. S. Pesquisa Artística na Universidade: implicações epistemológicas, políticas e institucionais. In: II Congresso Nacional de Pesquisadores em Dança (ANDA). São Paulo: UNESP, 2012, p. 1-10.

UNICAMP. Tabelas de Vencimentos. Campinas: DGRH, 2015. Disponível em http://www.dgrh.unicamp.br/documentos/tabelas-de-vencimentos, último acesso em 05/04/2016. 